\title{
Exploring Mental Models of Geothermal Energy among Laypeople in Germany as Hidden Drivers for Acceptance
}

\author{
Barbara S. Zaunbrecher ${ }^{* 1}$, Johanna Kluge ${ }^{2}$, Martina Ziefle ${ }^{3}$ \\ ${ }^{1}$ Human-Computer Interaction Center, Chair of Communication Science, RWTH Aachen University, \\ Campus-Boulevard 57, 52074 Aachen, Germany \\ e-mail: zaunbrecher@comm.rwth-aachen.de \\ ${ }^{2}$ Human-Computer Interaction Center, Chair of Communication Science, RWTH Aachen University, \\ Campus-Boulevard 57, 52074 Aachen, Germany \\ e-mail: kluge@comm.rwth-aachen.de \\ ${ }^{3}$ Human-Computer Interaction Center, Chair of Communication Science, RWTH Aachen University, \\ Campus-Boulevard 57, 52074 Aachen, Germany \\ e-mail: ziefle@comm.rwth-aachen.de
}

Cite as: Zaunbrecher, B. S., Kluge, J., Ziefle, M., Exploring Mental Models of Geothermal Energy among Laypeople in Germany as Hidden Drivers for Acceptance, J. sustain. dev. energy water environ. syst., 6(3), pp 446-463, 2018 , DOI: https://doi.org/10.13044/j.sdewes.d5.0192

\begin{abstract}
Geothermal energy provides an opportunity for sustainable energy supply. Nevertheless, some local geothermal energy projects face public opposition. To understand public acceptance or rejection of technologies, appropriate methods need to be applied depending on the project phase. This is exemplified for geothermal energy, for which an exploratory, qualitative study was conducted which uncovered laypeoples' mental models by assessing picture, word and colour associations on geothermal energy. Participants $(N=79)$ were asked for their associations on geothermal energy, as well as its general acceptance. The results revealed insights into cognitive conceptions as well as possible misconceptions. It could also be shown that participants' evaluation of associations in terms of positive emotions correlated positively with geothermal energy acceptance. The study verifies that assessing mental models can be valuable in early phases of understanding public acceptance, as acceptance-relevant criteria and topics to be addressed can be identified in order to adequately respond to people's concerns.
\end{abstract}

\section{KEYWORDS}

Renewables, Associations, Public perception, Communication, Drawings.

\section{INTRODUCTION}

Playing a marginal role among the renewable energies in Germany so far, geothermal energy projects continue to be installed in various regions of Germany, mostly along the North German Basin, the Molasse Basin (Southern Germany), or along the Upper Rhine Graben [1]. These projects are often accompanied by protests of local citizens, who argue against the projects. Their concerns include, for example, fear of earthquakes or dangers for the environment [2]. Also, some complain to be left uninformed about particular project details [3], or have little trust in the developers of the project concerning potential risks [4].

\footnotetext{
* Corresponding author
} 
Geothermal energy projects thus face similar opposition like other energy-related infrastructures, such as wind parks [5] or new transmission lines [6]. As discussed in [7], there is a need for further experimental research to complement qualitative studies on the acceptance of renewables energies. Meanwhile, there exists a rich body of literature on the acceptance of renewable energies in general and geothermal energy in particular. While there is already a profound knowledge across different energy-related technologies with regard to understanding the causes of opposition, the influence of acceptance-increasing measures is yet to be researched in the same depth [8]. It is advocated that beyond mere acceptance or rejection of energy-related infrastructure, other relations of people with this infrastructure need to be examined [9]. It is further argued that these should go beyond the Not-In-My-BackYard (NIMBY) effect and instead view renewable energy production as embedded in the complex socio-psychological context of social change [10].

Concerning, more specifically, geothermal energy, water usage and seismic activities due to drilling have been identified as possible barriers to widespread acceptance [11]. Resulting from first studies on the perception of this technology, it is concluded that especially risks and disadvantages should be addressed in the communication about geothermal energy [12]. Further studies confirmed a lack of knowledge in the public and underlined the need for dialogue and communication strategies [13].

Many of the studies on renewable energy acceptance are either qualitative case studies (e.g., $[14,15])$ or based on large-scale surveys (e.g., $[16,17])$. However, with a technology that is relatively new and still unknown to the majority of the public such as geothermal energy, it can be valuable to use more explorative, qualitative methods to gain insights into factors influencing acceptance, especially if these are still unknown for the technology in question. In this stage, especially underlying influential factors, which subliminally contribute to acceptance, are of interest. Because it is often unknown what affects participants in an early stage of technology diffusion [18], analysing spontaneous associations and emotions can uncover topics for research on social implications and possible acceptance barriers and benefits of a technology [12]. These associations are collectively referred to as "mental models" in this research, referring to emotions, knowledge and associations attached to a specific topic. A variety of studies uncovering mental models in relation to acceptance of energy-related technologies [19], Carbon (dioxide) Capture and Storage (CCS) [20] and climate change [21] have been conducted which found evidence for the close connection between acceptance and the willingness to adopt a technology on the one hand and positive or negative connotations within mental models on the other hand. Furthermore, they validated the elicitation of mental models from laypeople as a suitable method to identify misconceptions and topics needing to be addressed in (risk) communication concepts. Although geothermal energy has been researched from the social science and acceptance point of view, mental models of this technology have not yet been explored in detail.

Therefore, in this study, picture, word and colour associations on geothermal energy were collected, in order to identify hidden drivers that influence people's attitudes towards geothermal energy.

\section{PUBLIC PERCEPTION \& ACCEPTANCE OF GEOTHERMAL ENERGY}

Technology acceptance research has gained increasing importance in the last decades. Besides traditional acceptance models, numerous studies have set out to explain what influences acceptance, particularly in technical contexts. Among others, user diversity (e.g. domain knowledge, age, gender) [22-24], context (e.g. medical context, energy context, culture) $[25,26]$ or type of technology (e.g. large-scale technology, medical technology, information and communication technology) [27] have been identified as influential factors. 
But technology acceptance research has not only focused on small-scale technologies. Continuous protests against renewable energy infrastructures, built with the aim to decarbonize energy production, have put acceptance of energy-related infrastructure in the focus of technology acceptance research. Among those, geothermal energy acceptance has been investigated with different approaches and thematic foci.

Studies from Germany show that especially concerns about water pollution and seismic activity are connected with geothermal energy [28]. Studies comparing the perception of geothermal energy in different countries have found that transnationally, there are four main issues for the rejection of geothermal energy:

- Environmental issues;

- Financial issues;

- Missing involvement of citizens;

- NIMBY issues [29].

Besides, studies about the knowledge on geothermal energy in the public as well as about perceived risks and barriers have revealed that the general knowledge about geothermal energy is low. This leads to a higher risk perception and distrust regarding geothermal energy [12]. Knowledge about deep geothermal energy was identified as a crucial factor for acceptance, as it was found that informed people in contrast to people with a low information level about geothermal energy tend to have a higher acceptance for this technology [30]. Besides, a gender difference in the thematic focus in the context of geothermal energy systems was identified. While men mostly refer to economic and ecological aspects of the technology on a general level, women focus more on advantages and disadvantages that may concern them personally, as an analysis of web comments on the topic shows [31]. The low level of knowledge in the general public and thus the lack of acceptance for geothermal projects often arises from a lack of communication or information strategies [32].

Several studies have focused on the communication aspect in the context of geothermal energy projects. One proposal is a community engagement process, including an intense dialog with all stakeholders, in which the discussion with the general public plays an essential role [33]. Practical communication guidelines based on an empirical study with regard to communicative preferences (time, person providing the information, channel, and form of participation) in deep geothermal energy projects have also been provided [32].

For a successful and adequately tailored communication strategy, a deeper understanding of the communicative needs and thus underlying mental representations of geothermal energy is required to build a bridge between experts with a complex technical knowledge, and laypeople, who often base their evaluations on affective concerns and uncertainties.

While studies on mental models of geothermal energy are rare (with exception of [12]), they have been explored in other energy-related contexts such as nuclear power plants [34], or hydrogen energy [35], for single technologies such as computers [36] or more abstract topics such as climate change [21]. Mental models have been captured using drawings to elicit knowledge about computers [36], the perception of scientists [37], or electricity networks and involved actors [38]. Furthermore, word associations were used, e.g., in the context of geothermal energy [12] and hydrogen perception [35].

Concerning interrelations between mental models (associations) and acceptance, it was found that not only the content, but also the type of associations (concrete vs. abstract) differ between those persons who are rather accepting and those who are rejecting, in this case, nuclear power plants [34]. The mental models collected were able to, e.g., explain the dealing with errors and problem solving [36], identify stereotypes [37], provide rich input for communication strategies by uncovering misconceptions [39] 
and explain support or rejection of renewable energy infrastructure [38]. Thus, they have proven to "provide useful counterpoints to self-report data" [40].

\section{QUESTIONS ADDRESSED AND LOGICAL APPROACH}

This exploratory study aims at eliciting mental models of geothermal energy on the pictorial, verbal and colour level. In addition, it focuses on the question if mental models correlate with the acceptance of geothermal energy. Because there have been no studies so far on this particular topic, the study is designed as a first, exploratory investigation. The approach combines free association with a structured questionnaire to collect data on the participants' profiles.

\section{EXPLORATORY STUDY OF ASSOCIATIONS WITH GEOTHERMAL ENERGY}

A questionnaire was designed to record mental models and associations of geothermal energy technology (in terms of pictorial, verbal and colour associations). The questionnaire was handed to interested participants at information events about geothermal energy (university and public) and using personal networks. Participants were given a printed version of the questionnaire which they could fill out by themselves. They were asked to return the questionnaire to the research team in a closed envelope to guarantee anonymity. They were instructed to complete the questionnaire carefully and to the best of their knowledge. They were free to skip questions they could or did not want to answer. After data collection, the data of the questionnaires were transferred into a statistical software program - SPSS. Afterwards, the associations were analysed and interpreted against the background of geothermal energy acceptance.

\section{Questionnaire}

Data were collected using a pen-and-paper questionnaire (see Appendix). It contained a section on user characteristics (not discussed in detail in this paper), as well as questions on acceptance of geothermal energy and related mental models. Also, the age and gender of participants was assessed. Every participant answered the questions in the same order. Unless indicated otherwise, agreement to items was measured on a six point Likert-scale ( $1=$ strongly disagree, $6=$ strongly agree $)$.

Acceptance of geothermal energy. Acceptance of geothermal energy was measured using two items: "I think geothermal energy is a useful source of energy for Germany" and "I am against the use of geothermal energy, as the installation of the power plant/ the drilling is expensive". The two items correlate significantly $(r=-0.58, p \leq 0.01)$ and were thus combined to the factor "acceptance of geothermal energy" (calculated as mean score of the two items).

Mental models of geothermal energy. Pictorial representations of geothermal energy were assessed by asking participants to draw a picture "that comes to your mind when you think of geothermal energy". No further instructions or information on the technology were given, in order not to bias participants. Afterwards, participants were asked to rate this picture emotionally on a five-point scale ranging from " 1 = characterized by very negative associations" to " $5=$ characterized by very positive associations".

Word associations were elicited by asking the participants to note down four verbal terms that they spontaneously associate with geothermal energy. They were asked to rate each of their associated words on a five-point scale ranging from " $1=$ very negative" to " $5=$ very positive". The colour association was elicited by asking "Which colour do you 
spontaneously associate with geothermal energy?" (free answering format). Colour associations were asked for to provide insights for the design of information material on geothermal energy, as the use of primarily associated colours could support the communication of technical information to laypersons.

\section{Participants}

In total, 79 participants took part in the study. Participation was voluntary and participants were recruited among the general public and visitors of information events about geothermal energy. $58 \%$ of the sample were male and $39 \%$ female, with a mean age of 37.5 years [Standard Deviation $(\mathrm{SD})=13.27$, range between 19 und 79 years].

\section{Analysis of mental models}

Different procedures were employed to analyse pictorial, verbal and colour associations.

Analysis of picture associations. After a first viewing of the pictures, meta-categories were defined which were based on the most prominent theme of the pictures: implementation, process and an "abstract" category. Within these categories, subcategories were defined: for the implementation, three stages were established, the "power station" as the spatially broadest category, the "house" as a more concrete implementation and lastly the "single technical element" as the narrowest implementation. Technically, deep and surface geothermics, as represented by pictures with power stations or houses, have to be considered as two different technologies, but as the study focused on the scope of the mental representations of the participants, it was decided for the different technologies to represent different types of implementation.

The category "process" was subdivided into "drilling" and "circulation", both referring to a more general perspective and not concentrating on the concrete infrastructure involved, but rather on stages in the process of establishing a geothermal power plant.

The third category included drawings that depicted a generic perspective on geothermal energy and focused on the type of energy involved, e.g. representing "heat" in contrast to "wind" or "sun".

The category descriptions were then given to two other raters, who were asked to sort all pictures in the best-fitting category to control for subjectivity in the categorization. An overall agreement of $69 \%$ with rater 1 and $67 \%$ with rater 2 was achieved. Considering the degree of abstractness of the pictures, this was considered sufficient to use the categories for further analysis. The pictures were further examined more closely with a focus on the single elements contained in each picture. For the analysis, a list was compiled containing all features that were identified in the pictures (e.g. house, pipes, heating, tree, sun, etc.). For each picture, three raters decided independently if an element was present or absent. In a next step, the evaluations of the three raters were compared and each picture was re-tagged with the present or absent elements, according to the decision of the majority of the raters.

Analysis of word associations. Word associations were categorized according to negative (1-2), neutral (3) or positive (4-5) ratings, depending on the rating that the participants had assigned to them. Words which had not received a rating as well as those that were illegible were excluded from the analysis. For the report here, word associations were translated from German into English.

Analysis of colour associations. Colour associations were sorted by frequency of mentions. Colours which had only been mentioned once were grouped in the category 
"others". Mentions that did not refer to a colour (e.g., "none, because it is dark under ground") were excluded.

\section{Results}

First, a detailed description of the pictorial associations is given. Next, the word associations are analysed followed by the colour associations.

Pictures. Overall, 60 drawings were collected from the 79 participants (19 returned questionnaires did not contain a drawing). The pictures were then categorized according to the procedure described above. The categories, number of pictures included as well as sample pictures for each category are shown in Table 1.

Table 1. Participants' drawings representing geothermal energy according to categories (emotional evaluation: $1=$ very negative, $5=$ very positive)

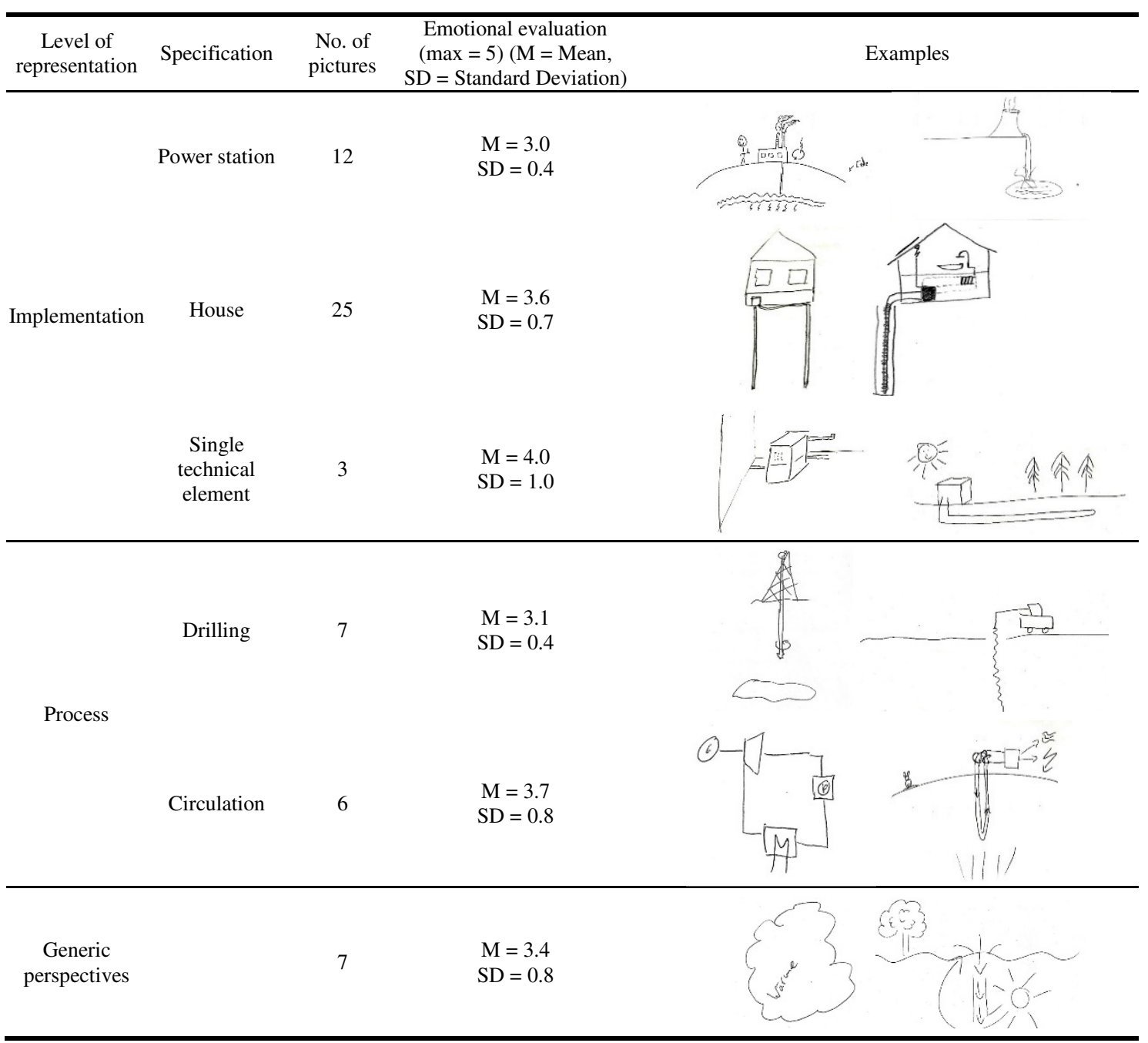

Overall, participants rated their pictures neutral to positive $(\mathrm{M}=3.4, \mathrm{SD}=0.7)$. The categorization shows that two thirds of the participants associated different types of implementations of geothermal energy (power station, house, single technical element). The most often associated type of implementation was "house" (representing surface geothermics). The pictures varied in detail, from simple drawings of houses with pipes to the ground to complex depictions of a house with pipes, radiators and other technical elements (Figure 1).

The second most often associated implementation type was "power station", symbolizing deep geothermics. 13 participants associated parts of the process of 
geothermal energy, of which seven pictures representing drilling and six focused on the circulation within the system.
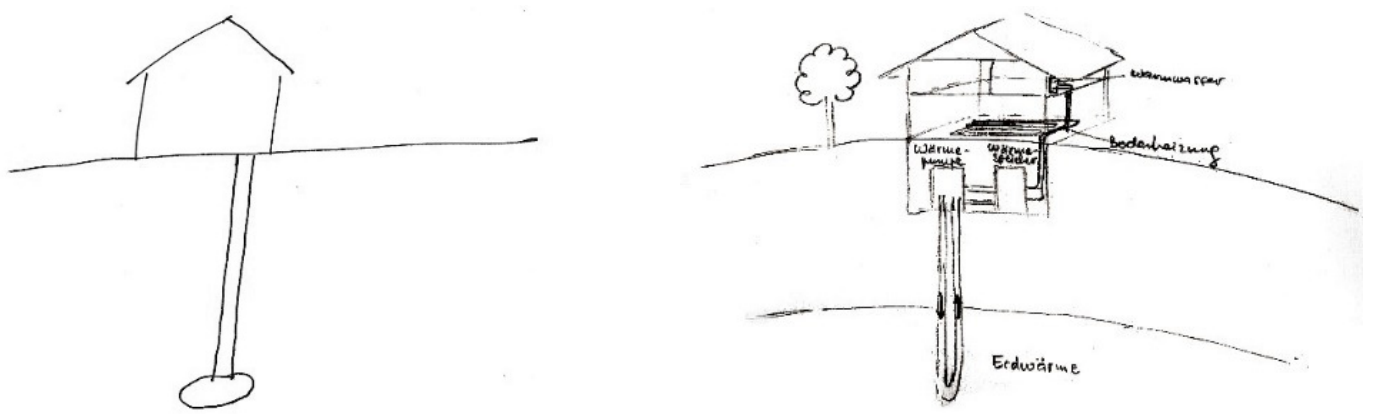

Figure 1. Sample pictures depicting "surface geothermics" in different degree of detail

Figure 2 shows two sample pictures which depicted the drilling needed to reach the hot water which can serve as the source of energy for geothermics. These pictures reflect at least some basic knowledge about the functionality and technical background of geothermal power plants. They could also be a reflection of the media coverage about geothermal energy, in which the drillings were made responsible for damages to houses [41].
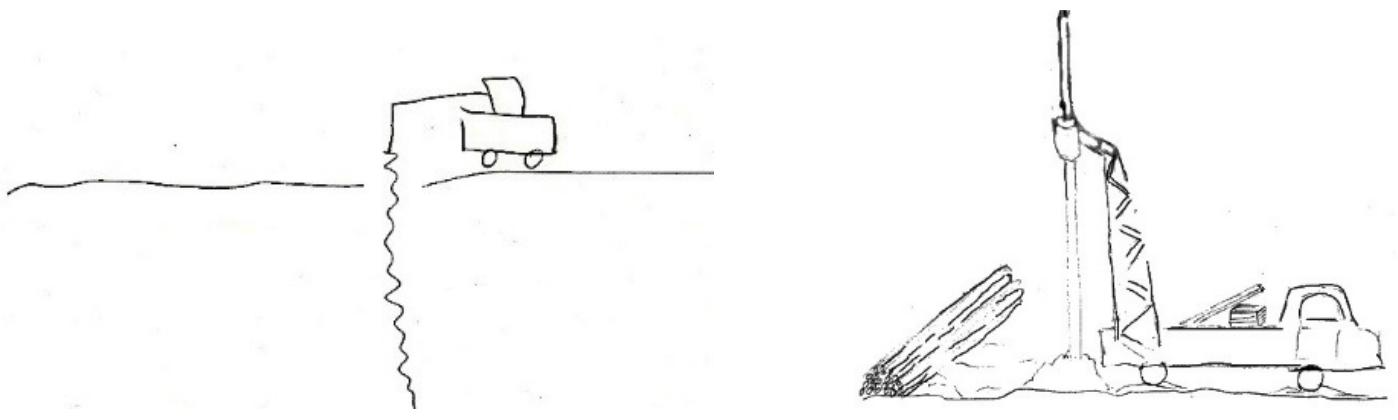

Figure 2. Samples for pictures depicting "drilling"

Seven pictures contained an abstract perspective on geothermal energy, e.g., abstract depictions of heat as energy source for this technology in contrast to, e.g., wind or the sun. Sample pictures for this category are shown in Figure 3.

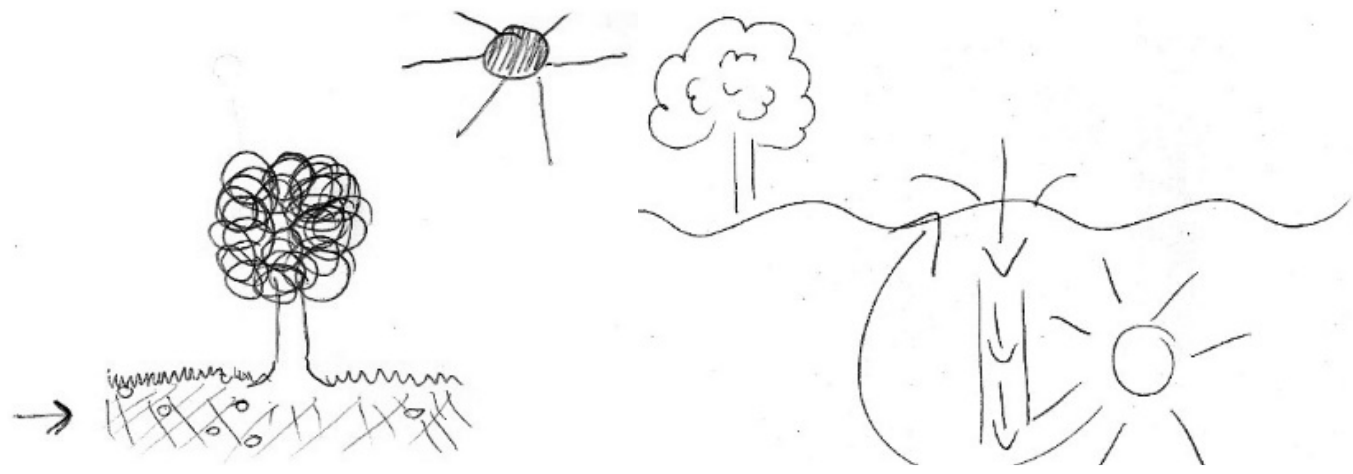

Figure 3. Samples for pictures depicting an abstract perspective on geothermal energy

Those pictures depict only basic knowledge (e.g., that geothermal energy is in some way related to energy from the "ground") and indicate that it cannot be assumed that geothermal energy is widely known. 
Considering the single elements present in the pictures, the earth was the element that was drawn most often and was found in $75 \%$ of all pictures (Figure 4). Apparently, the central role of the earth as energy source was present for the majority of the participants. The necessity of drilling a hole in the ground to be able to access hot water needed for energy production was depicted in $65 \%$ of all pictures, in $44 \%$, even multiple drilling holes were considered. Half of the pictures contained an intermediate technical device, showing that participants had basic knowledge of the technical details of geothermal energy (e.g. that a heat pump is required). Some pictures also uncovered misconceptions, e.g., that drillings are as deep as the earth's core (Figure 5) or that lava is used as a source of heat (Figure 6).

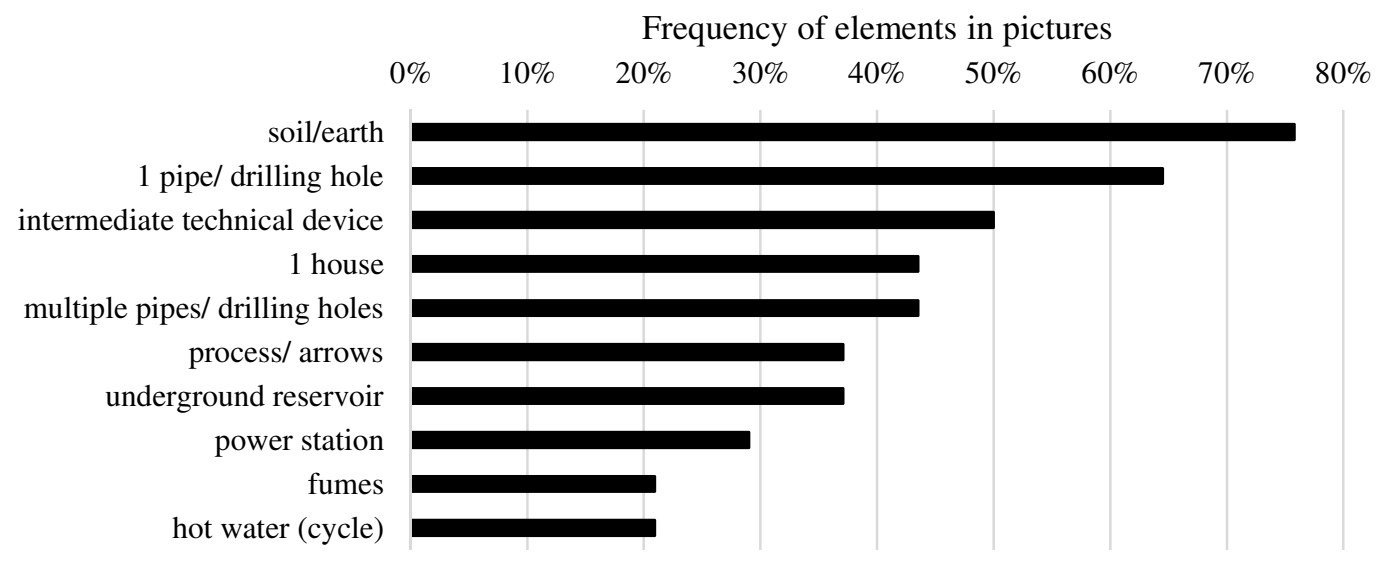

Figure 4. Ten most frequent elements identified in the pictures $(n=60)$

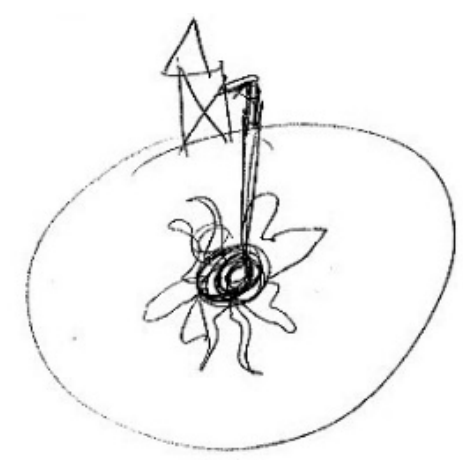

Figure 5. Drilling to the earth's core

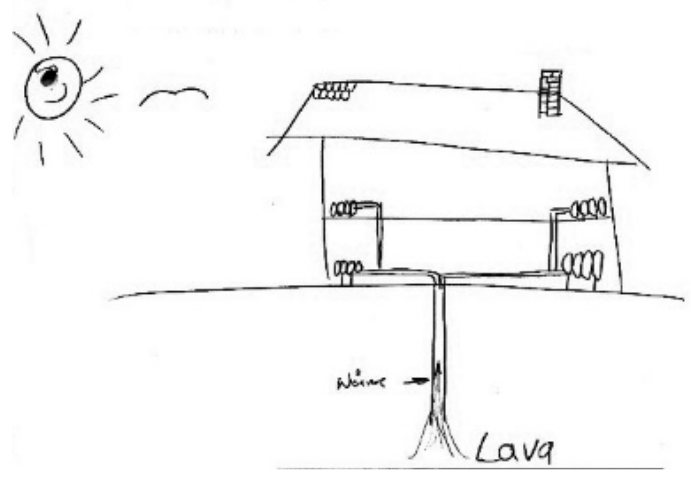

Figure 6. Lava used as a source of energy

Overall, a significant correlation was found between the emotional evaluation of the pictures and the acceptance of geothermal energy $(r=0.37, p \leq 0.01)$. 
Word associations. 49 of 233 word associations were rated negatively ("very negative" or "negative"). They were condensed into a "word cloud" (wordle.net, Figure 7). The cloud reflects the frequency with which the words were mentioned, the bigger the font, the more mentions (reference: "drilling" was mentioned 5 times).

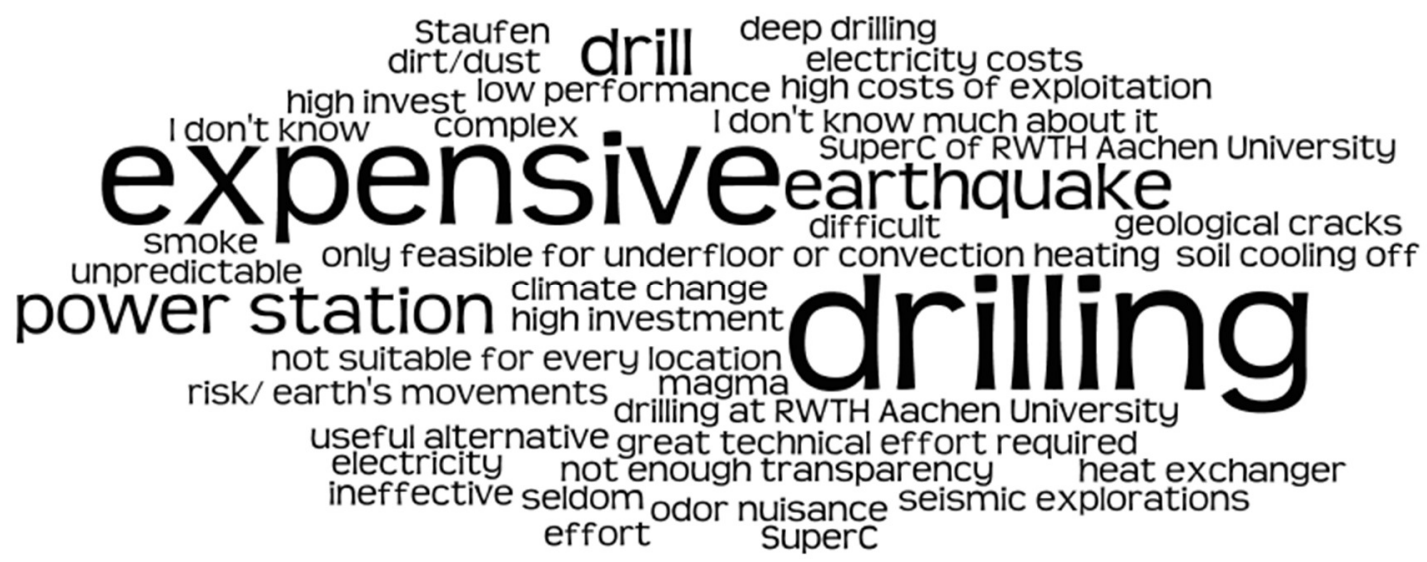

Figure 7. Word cloud displaying negative associations with geothermal energy

Especially the drilling process itself has negative connotations. Further negative associations are also connected to the drilling process or associated risks with it, for example high costs (and the possibility of failure, "unpredictable") and danger of earthquakes. Also, it is noteworthy that two unsuccessful geothermal projects were among the negative associations, a project at the local university of Aachen "SuperC", as well as "Staufen", a city in Southern Germany in which creeks in buildings are assumed to be the result of geothermal drilling activities [42]. Interestingly, "power station" also seems to evoke negative connotations, although it is mentioned in the context of renewable energies. "Useful alternative?" was formulated as a question, thus displaying uncertainty about the usefulness of the technology.

67 of the 233 associations received a neutral rating, they are displayed in Figure 8 (reference for frequency: drilling was mentioned 9 times). Prominent associations include a translation of the term "geothermal energy" (terrestrial heat), as well central concepts that are significant for geothermal energy, such as "heat", "heating" or "electricity".

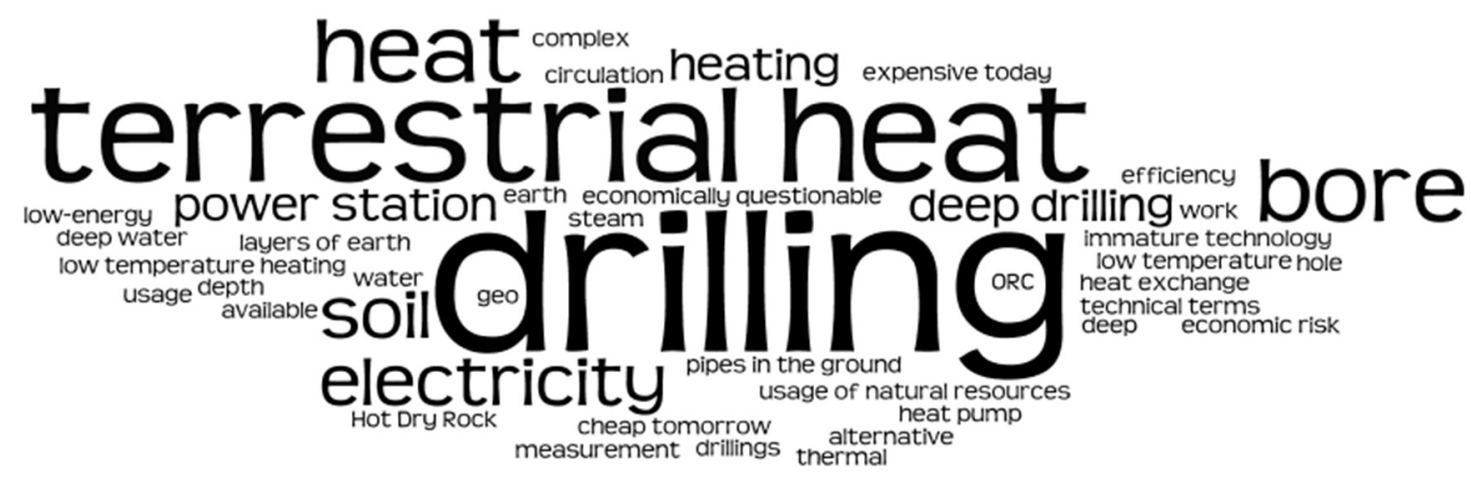

Figure 8. Word cloud displaying neutral associations with geothermal energy

The majority of word associations (117 of 233) were given a positive rating ("positive" or "very positive"). The term that was most often associated positively was "terrestrial heat" (12 times). The summary in Figure 9 shows that geothermal energy itself, terrestrial heat, has positive connotations. Furthermore, the supply of heating (e.g., 
"heat", "warm", "heating") presents a second prominent field of associations. The word cloud with positive associations is also characterized by words referring to the renewable character of geothermal energy and its low impact on the environment (e.g., "sustainable", "environmental protection", "renewable energy", "green energy", "does not destroy landscape").

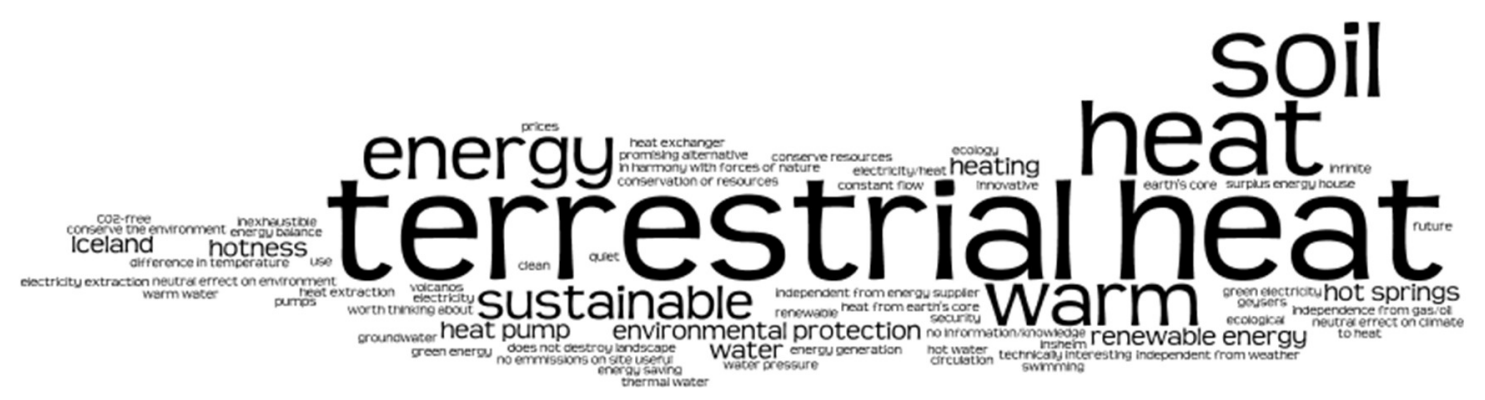

Figure 9. Word cloud displaying positive associations with geothermal energy

From the word associations, it is possible to identify a trade-off between two major traits that are associated with geothermal energy: the renewable, low-impact character on the one hand and the insecure, possibly risky and expensive drilling process that is needed on the other hand.

Colour associations. Concerning colour associations, red was the most frequently associated colour (Figure 10) followed with some distance by green and orange, followed by brown and yellow. "Other" associations include single mentions such as "white-blue" or "black and white". It is noteworthy that among the most frequently mentioned colours, there is a majority of "warm" colours, often associated for example with heat (red, orange, yellow). Thus, heat from the earth as the main technical principle of geothermal energy is reflected in the colour associations. Besides, the fact that the colour green is also mentioned regularly could represent the "green" image of geothermal energy in the sense of a renewable resource.

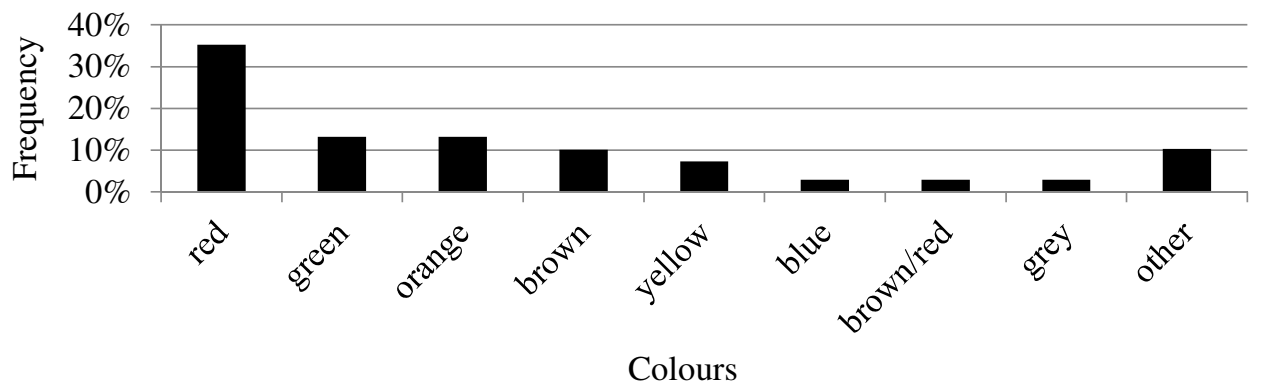

Figure 10. Colour associations for geothermal energy $(n=68)$

Acceptance of geothermal energy. Acceptance of geothermal energy was overall high, indicated by a mean value of $4.4(\mathrm{SD}=0.9)$ for the factor "acceptance of geothermal energy".

A correlation analysis (Spearman's rank correlation coefficient) between acceptance of geothermal energy and rating of pictures and word associations by the participants on the emotive scale was conducted to uncover measurable relations between affect (related to the mental model) and general attitude towards geothermal energy. For word ratings, a mean value was calculated across all word associations by a participant. Emotional picture rating and acceptance correlated with $r=0.35(p \leq 0.01, n=59)$, emotional word 
rating and geothermal energy acceptance correlated with $r=0.43(p \leq 0.01, n=63)$. The positive correlation indicated that there is at least a moderate correlation of the type that the more positive participants' associations with geothermal energy, the more positive their attitude towards geothermal energy was (and vice versa). Word and picture ratings correlated at $r=0.38(p \leq 0.01, n=61)$, which indicated that the more positive participants' rated their drawings, the more positive they rated their word associations (and vice versa). The data show that participants' mental models on the word and the picture level corresponded (although only moderately) to each other.

\section{DISCUSSION}

This exploratory study aimed at uncovering participants' mental models of geothermal energy on three different levels: pictorial, verbal and in terms of colour. The idea behind this approach was that there might be hidden drivers "behind" specifically stated public acceptance which are influenced by individual risk tolerance, fuzzy fears and concerns, but also by perceptions of usefulness of the technology. Furthermore, it was hypothesized that this implicit knowledge is not necessarily conscious, however, it might be reflected in implicit metaphors and circumscriptions (colour, verbal terms and pictures). Indeed, the results provide insights into those hidden acceptance-relevant concepts and show how they are represented in the different types of associations. This, in turn, is valuable for the development of a sound methodological concept to elicit mental models of relatively unknown technologies in the general public.

First, the main question was in how far it would be possible to identify acceptance-relevant concepts for the communication of geothermal energy. From the picture associations, it can be deduced that near-surface geothermal energy was the most known application of geothermal energy in the sample. This can be explained by the fact that the participants were mostly based in an area where there is no geothermal power plant, so that this type of geothermal energy use is not as present in their minds. In large-scale applications, it was known that a type of power station is needed for the conversion into heat or electricity. However, despite a general positive image of geothermal energy, power stations were negatively denoted. This was evident from the evaluation of the pictures as well as by the words associations. Apparently, there exists a particular sensitivity towards power stations in the public, which could be due to their background in fossil or nuclear applications. Nuclear power stations have been shown to evoke negative emotions [43] and, as a consequence, decrease acceptance [44]. These attitudes seem to be transferred to geothermal energy. In this line of argumentation, the prevailing negative image of power plants then "overshadows" even the otherwise positive association of a renewable energy. Bearing in mind that these are used for large-scale application of geothermal energy, with a greater number of residents affected, they present a possible barrier of adoption that should be addressed in information and communication concepts.

Further essential components of geothermal energy plants are the bore holes, which require deep drilling. "Drilling" was also one of the most dominant elements in the pictures representing a central aspect of the mental model of geothermal energy. This could be the result of the extensive media coverage of incidents in past geothermal projects, which were ascribed to the drilling.

The drilling process was rated neutral to negative in the picture and word associations: the drawings which depicted drilling as a central element were rated less positive than others and drilling was the most prominent among the negative word associations. Still, there are mixed opinions in the literature (e.g. [41]) if the drilling process is related to the frequency of earthquakes or not - for the public it is important that they can trust public authorities with respect to a transparent and open discussion about possible benefits, but also fears. Giardini [41] resumes: 
"The public reacts with a vengeance if it perceives that a known problem has been hidden. More than this, earthquakes invariably raise primordial fears. Waking up the sleeping terror that lurks in the deep is the plot of numerous horror movies; here it has an all-too-real meaning." (p. 274)

Moreover, there was evidence for concrete details about the technology and infrastructure involved in geothermal energy usage in the drawings (e.g. heat pumps), which were, however, not named in the association task. An explanation could be that the idea of an "intermediate element" is present in the participants' mind, but they lack knowledge of the precise name of this element.

The associations also helped to identify trade-offs. Especially in the verbal association, two conflicting poles exist: on the one hand, the positively rated environmental impact of geothermal energy and on the other hand the negatively evaluated high invest and the necessary infrastructure. This impression is a possible explanation for the ambivalent attitude of the participants towards the technology.

Overall, the significant correlations between different types of associations as well as associations and acceptance indicate that the drawings present an adequate method to gain insight into the mental representation of geothermal energy and also the acceptance of this technology. However, the evaluation of the different types of associations is challenging, especially when it comes to a comparison, as associations of varying degrees of concreteness were mentioned depending on the type of association.

Finally, the methodology applied needs to be critically discussed. The chosen method was not only able to uncover hidden mental models, but also revealed interesting insights in the nature of cognitive and affective representations. On the one hand, there were concepts which were represented in more than one, in some cases even all, association-types. These include for example power stations, which were clearly identifiable in the pictures and the word associations. Heat was another example: it was symbolized by radiators in the drawings, as specific word in the word associations and could also be found in the colour associations (as symbolized by the colours red, orange and yellow) which shows how one association is expressed differently, depending on the type of association. These differences provide a valuable means to uncover different facets of a mental representation.

On the other hand, there were associations which were prominent in one type of association task, but not in others. It was for example possible for the participants to express ideas about the environmental impact of geothermal energy on a verbal level, which could not have been done as easily using a drawing. Therefore, the assessment of mental models can benefit from using different methodological approaches, to be able to capture a more complete picture.

Further research could focus on the interpretation of the pictures from the icon-theory perspective, to explore how the participants depicted their mental representation of geothermal energy and which elements they used. A follow-up study should also focus on user diversity and effects on acceptance - then however, more participants and pre-selected representations of geothermal energy are needed to gain further information on the influence of user factors and the mental representation on acceptance. Regarding the sample size, the number of participants was considered suitable for a first, exploratory investigation. A quantitative follow-up study needs, of course, more participants and a more balanced sample regarding gender and age distribution. The male participants were slightly overrepresented in our sample, possibly the technical topic attracted more male than female participants. This should be kept in mind with regard to the generalizability of the data.

Besides, we refrained from structuring the word associations any further, for example in thematic categories, in order to stay as close as possible to the original data and 
minimize the influence of the researcher. Further structuring could, however, provide insightful information on different thematic focus points of the associations.

Naturally, one might critically argue that those qualitative and indirect measures to uncover mental models miss the empirical rigor in comparison to quantitative measures and an inferential statistical testing. This criticism is justifiable as analyses and interpretation of participants' mental models include presumptions and constructions without "experimental control". On the other hand, only by these methods mental models can be made visible at all. The explorative methods are mandatory in order to detect affective and hidden acceptance drivers, which is especially important in early phases of understanding acceptance factors. In the next step, a cross validation with a quantitative modelling is needed. On the base of the findings here, a conjoint study is planned in which it will be further investigated in how far these underlying models relate to the intention to use geothermics.

\section{CONCLUSION}

In this exploratory study, mental models of geothermal energy were assessed using a qualitative approach. Participants' associations showed that knowledge about geothermal energy is diverse, ranging from very basic representations to complex processes. It was further shown that the more negative participants' (self-rated) imagery associations with geothermal energy, the more negative their attitude towards geothermal energy was. This referred mostly to deep geothermal energy, for which "drilling" and "power stations" represented especially negative associations. The different methods chosen to elicit the mental models were insightful to uncover different aspects of mental representations of geothermal energy. Regarding the communication about geothermal energy, the sustainable generation of heat can serve as a positive characteristic of this technology, while the costs, the drilling procedure, the fear of earthquakes and the power station should be taken into account as possible drawbacks which laypeople associate.

\section{ACKNOWLEDGEMENTS}

Thanks to Julian Halbey and Simon Himmel for research assistance. Further thanks to Sylvia Kowalewski for valuable advice on research design and analysis. Special thanks also to Manfred Zeidler for generously sharing his time.

This work has been funded partly by the German Federal Ministry for Industry and Energy (Project TIGER, BMWi, no. FKZ 0325413A) and partly by the Excellence initiative of German Federal and State (Project UFO, Urban Future Outline).

\section{REFERENCES}

1. Weber, J., Ganz, B., Schellschmidt, R., Sanner, B. and Schulz, R., Geothermal Energy use in Germany, Proceedings of the World Geothermal Congress, Melbourne,

Australia, https://www.geothermal-energy.org/pdf/IGAstandard/WGC/2015/01045.pdf， 2015, [Accessed: 16-January-2015]

2. Rost, A., Geothermal Energy: Protest against Geothermal Energy (in German), fr-online.de, 2015, http://www.fr-online.de/main-taunus/geothermie-protest-gegengeothermie, 1472862,29591354.html, [Accessed: 16-January-2015]

3. Geothermal Energy: Protest from Massenheim (in German), Allgemeine Zeitung, 2015, http://www.allgemeine-zeitung.de/lokales/mainz/hochheim/geothermieprotest-aus-massenheim_15150844.htm, [Accessed: 26-April-2016]

4. Substantial protest by Citizens against Geothermal Energy (in German), Morgenweb, 2012, http://www.morgenweb.de/mannheim/stadtteile/rheinau-hochstatt/geothermie -stosst-auf-massiven-protest-der-burger-1.550420, [Accessed: 16-January-2015] 
5. Devine-Wright, P. and Howes, Y., Disruption to place Attachment and the protection of Restorative Environments: A Wind Energy Case Study, J. Environ. Psychol., Vol. 30, No. 3, pp 271-280, 2010, https://doi.org/10.1016/j.jenvp.2010.01.008

6. Cotton, M. and Devine-Wright, P., Putting Pylons into Place: A UK Case Study of Public Perspectives on the impacts of high Voltage overhead Transmission Lines, J. Environ. Plan. Manag., Vol. 56, No. 8, pp 1225-1245, 2013, https://doi.org/10.1080/09640568.2012.716756

7. Wüstenhagen, R., Wolsink, M. and Bürer, M. J., Social acceptance of Renewable Energy Innovation: An Introduction to the Concept, Energy Policy, Vol. 35, No. 5, pp 2683-2691, 2007, https://doi.org/10.1016/j.enpol.2006.12.001

8. Cohen, J. J., Reichl, J. and Schmidthaler, M., Re-focussing research efforts on the Public acceptance of Energy Infrastructure: A Critical Review, Energy, Vol. 76, pp 4-9, 2014, https://doi.org/10.1016/j.energy.2013.12.056

9. Batel, S., Devine-Wright, P. and Tangeland, T., Social acceptance of Low Carbon Energy and associated Infrastructures: A Critical discussion, Energy Policy, Vol. 58, pp 1-5, 2013, https://doi.org/10.1016/j.enpol.2013.03.018

10. Batel, S. and Devine-Wright, P., Towards a better understanding of People's responses to Renewable Energy Technologies: Insights from Social Representations Theory, Public Underst. Sci., Vol. 24, No. 3, pp 311-325, 2015, https://doi.org/10.1177/0963662513514165

11. Dowd, A.-M., Boughen, N., Ashworth, P. and Carr-Cornish, S., Geothermal Technology in Australia: Investigating Social acceptance, Energy Policy, Vol. 39, No. 10, pp 6301-6307, 2011, https://doi.org/10.1016/j.enpol.2011.07.029

12. Kluge, J., Kowalewski, S. and Ziefle, M., Inside the User's Mind - Perception of risks and benefits of unknown Technologies, exemplified by Geothermal Energy, Digital Human Modeling, Applications in Health, Safety, Ergonomics and Risk Management: Human Modeling (Duffy, V. G., ed.), Springer International Publishing, pp 324-334, 2015.

13. Pellizzone, A., Allansdottir, A., De Franco, R., Muttoni, G. and Manzella, A., Exploring Public engagement with Geothermal Energy in Southern Italy: A Case Study, Energy Policy, Vol. 85, pp 1-11, 2015, https://doi.org/10.1016/j.enpol.2015.05.002

14. Waldo, A., Offshore Wind Power in Sweden - A Qualitative analysis of attitudes with particular Focus on opponents, Energy Policy, Vol. 41, pp 692-702, 2012, https://doi.org/10.1016/j.enpol.2011.11.033

15. Ogilvie, M. and Rootes, C., The impact of Local Campaigns against Wind Energy developments, Environ. Polit., Vol. 24, No. 6, pp 874-893, 2015, https://doi.org/10.1080/09644016.2015.1063301

16. Meyerhoff, J., Ohl, C. and Hartje, V., Preferences for the design of Windparks in the Landscape - Results from an Online Study in Germany (in German), Arbeitspapiere zum Management in der Umweltplanung, Vol. 22, 2008, http://www.bauphysik.tu-berlin.de/fileadmin/a0731/uploads/publikationen/working papers/WP_24_Meyerhoff_Ohl_Hartje_Praeferenzen_fuer_die_Gestaltung_der_Wi ndkraft.pdf, [Accessed: 16-January-2015]

17. Johansson, M. and Laike, T., Intention to respond to Local Wind Turbines: The Role of attitudes and Visual perception, Wind Energy, Vol. 10, No. 5, pp 435-451, 2007, https://doi.org/10.1002/we.232

18. Kowalewski, S., Arning, K., Minwegen, A., Ziefle, M. and Ascheid, G., Extending the Engineering trade-off analysis by integrating User preferences in Conjoint analysis., Expert Syst. Appl., Vol. 40, No. 8, pp 2947-2955, 2013, https://doi.org/10.1016/j.eswa.2012.12.010

19. Zaunbrecher, B. S., Bexten, T., Wirsum, M. and Ziefle, M., What is stored, why, and how? Mental Models, Knowledge, and Public acceptance of Hydrogen Storage, 


Energy Procedia, $\quad$ Vol. $\quad 99, \quad$ pp $108-119, \quad 2016$,
https://doi.org/10.1016/j.egypro.2016.10.102

20. Wallquist, L., Visschers, V. H. M. and Siegrist, M., Lay concepts on CCS deployment in Switzerland based on qualitative Interviews, Int. J. Greenh. Gas Control, Vol. 3, No. 5, pp 652-657, 2009, https://doi.org/10.1016/j.ijggc.2009.03.005

21. Bostrom, A., Morgan, M. G., Fischhoff, B. and Read, D., What do People know about Global Climate Change?, Mental Models, Risk Anal., Vol. 14, No. 6, pp 959-970, 1994, https://doi.org/10.1111/j.1539-6924.1994.tb00065.x

22. Busch, T., Gender differences in Self-efficacy and attitudes toward Computers, J. Educ. Comput. Res., Vol. 12, No. 2, pp 147-158, 1995, https://doi.org/10.2190/H7E1-XMM7-GU9B-3HWR

23. Ziefle, M. and Schaar, A. K., Technical expertise and its influence on the acceptance of Future Medical Technologies: What is influencing what to which extent?, HCI in Work and Learning, Life and Leisure, G. Leitner (Hitz, M. and Holzinger, A., eds), Springer Berlin Heidelberg, pp 513-529, 2010.

24. Wilkowska, W. and Ziefle, M., User diversity as a challenge for the integration of Medical Technology into Future Home Environments, Hum.-Centred Des. E-Health Technol.: Concepts Methods and Appl., pp 95-126, 2011, https://doi.org/10.4018/978-1-60960-177-5.ch005

25. van Heek, J., Arning, K. and Ziefle, M., Where, wherefore, and how? - Contrasting two surveillance Contexts according to acceptance, $6^{\text {th }}$ International Conference on Smart Cities and Green ICT Systems (Smartgreens 2017), SCITEPRESS - Science and Technology Publications, pp 87-98, Porto, Portugal, 2017, https://doi.org/10.5220/0006362400870098

26. Mallat, N., Rossi, M., Tuunainen, V. K. and Öörni, A., The impact of use Context on Mobile Services acceptance: The Case of Mobile ticketing, Inf. Manage., Vol. 46, No. 3, pp 190-195, 2009, https://doi.org/10.1016/j.im.2008.11.008

27. Zaunbrecher, B. S., Kowalewski, S. and Ziefle, M., The willingness to adopt Technologies: A Cross-sectional Study on the influence of Technical Self-efficacy on acceptance, in Human-Computer Interaction, Applications and Services, Springer, pp 764-775, 2014, https://doi.org/10.1007/978-3-319-07227-2_73

28. Brian, M., Creating Trust through focused Communication: Special Issue on Geothermal Energy (in German), bbr Leitungsbau, Brunnenbau, Geothermie, Vol. 64, pp 72-74, 2013.

29. Reith, S., Kölbel, T., Schlagermann, P., Pellizzone, A. and Allansdottir, A., Public acceptance of Geothermal Electricity Production, GEOELEC Deliv. $N^{\circ} 44$ Rep. Public Accept., 2013, http://www.syntropolis.net/media/library/Public_acceptance _of_geotherman_electricity_production.pdf, [Accessed: 16-January-2015]

30. Kowalewski, S., Borg, A., Kluge, J., Himmel, S., Trevisan, B., Eraßme, D., Ziefle, M. and Jakobs, E.-M., Modeling the influence of Human Factors on the Perception of Renewable Energies, Taking Geothermics as Example, Proceedings of the $5^{\text {th }}$ International Conference on Applied Human Factors and Ergonomics AHFE 2014, Kraków, Poland, pp 1884-1891, 2014.

31. Trevisan, B., Eraßme, D., Hemig, T., Kowaleski, S., Kluge, J., Himmel, S., Borg, A., Jakobs, E.-M. and Ziefle, M., Facebook as a Source for Human-centered engineering: Web mining-based Reconstruction of Stakeholder perspectives on Energy Systems, Proceedings of the $5^{\text {th }}$ International Conference on Applied Human Factors and Ergonomics AHFE 2014, Kraków, Poland, pp 5688-5699, 2014.

32. Kluge, J. and Ziefle, M., As simple as possible and as Complex as necessary A Communication Kit for Geothermal Energy Projects, Proceedings of the HCIBGO 2016: HCI in Business, Government, and Organizations: Information Systems, pp 171-182, Toronto, Canada, 2016. 
33. Wallquist, L. and Holenstein, M., Engaging the Public on Geothermal Energy, Proceedings of World Geothermal Congress, Melbourne, Australia, pp 19-25, 2015, https://pangea.stanford.edu/ERE/db/WGC/papers/WGC/2015/02032.pdf, [Accessed: 16-January-2015]

34. Keller, C., Visschers, V. and Siegrist, M., Affective Imagery and acceptance of replacing Nuclear Power Plants, Risk Anal., Vol. 32, No. 3, pp 464-477, 2012, https://doi.org/10.1111/j.1539-6924.2011.01691.x

35. Sherry-Brennan, F., Devine-Wright, H. and Devine-Wright, P., Public understanding of Hydrogen Energy: A Theoretical approach, Energy Policy, Vol. 38, No. 10, pp 5311-5319, 2010, https://doi.org/10.1016/j.enpol.2009.03.037

36. Denham, P., Nine- to Fourteen-year-old Children's Conception of Computers using Drawings, Behav. Inf. Technol., Vol. 12, No. 6, pp 346-358, 1993, https://doi.org/10.1080/01449299308924399

37. Finson, K. D., Drawing a Scientist: What we do and do not know after fifty years of Drawings, Sch. Sci. Math., Vol. 102, No. 7, pp 335-345, 2002, https://doi.org/10.1111/j.1949-8594.2002.tb18217.x

38. Devine-Wright, H. and Devine-Wright, P., Social representations of Electricity Network Technologies: Exploring Processes of anchoring and objectification through the use of Visual Research Methods, Br. J. Soc. Psychol., Vol. 48, No. 2, pp 357-373, 2009, https://doi.org/10.1348/014466608X349504

39. Leiserowitz, A., Communicating the Risks of Global Warming: American Risk Perceptions, affective Images, and interpretive Communities, (Moser, S. and Dilling, L., eds.), Communication and Social change: Strategies for dealing with the Climate Crisis, Cambridge University Press, pp 44-63, 2007.

40. Joffe, H., Risk: From Perception to Social Representation, Br. J. Soc. Psychol., Vol. 42, No. 1, pp 55-73, 2003, https://doi.org/10.1348/014466603763276126

41. Giardini, D., Geothermal Quake risks must be faced, Nature, Vol. 462, No. 7275, pp 848-849, 2009, https://doi.org/10.1038/462848a

42. Ruf, J., Staufen and the Geothermal Cracks (in German), Welt Online, https://www.welt.de/regionales/stuttgart/article126015139/Staufen-und-die-Geother mie-Risse.html, [Accessed: 20-March-2014]

43. Visschers, V. H. M., Keller, C. and Siegrist, M., Climate change benefits and Energy Supply benefits as determinants of acceptance of Nuclear Power Stations: Investigating an Explanatory Model, Energy Policy, Vol. 39, No. 6, pp 3621-3629, 2011, https://doi.org/10.1016/j.enpol.2011.03.064

44. Peters, E. and Slovic, P., The Role of affect and Worldviews as orienting dispositions in the perception and acceptance of Nuclear Power, J. Appl. Soc. Psychol., Vol. 26, No. 16, pp 1427-1453, 1996, https://doi.org/10.1111/j.1559-1816.1996.tb00079.x 


\section{APPENDIX}

\section{Questionnaire [Translated version, original language: German] \\ Dear participant,}

first of all we would like to thank you for participating in this survey and supporting our research project. This questionnaire assesses your personal view of geothermal energy. Even if you do not know a lot about this technology, your opinion is valuable to us. There are no right or wrong answers to the questions, only your personal opinion counts. Please answer the questionnaire honestly and carefully and complete all questions. Your data will be treated anonymously and will only be used in the context of this research. It will be ensured that there is no possibility to identify you from the data. The time to complete the questionnaire is around 10 to 15 minutes.

[Questions on user diversity omitted]

\section{Attitude towards geothermal energy}

The following questions deal specifically with geothermal energy. Please indicate how much you agree to the following statements:

(Answers measured on a 6-point Likert-scale: strongly disagree - disagree - slightly disagree - slightly agree - agree - strongly agree)

- I feel well-informed about geothermal energy;

- I think geothermal energy is a useful source of energy for Germany;

- I am against the use of geothermal energy, as the installation of the power plant/ the drilling is expensive.

\section{Expose to geothermal energy}

- I use geothermal energy for my home or know someone who does; (yes/no)

- I live near a geothermal power plant. (yes/no)

\section{Mental model}

3.1 Which picture comes to your mind when you think of geothermal energy? Please make a drawing!

[space for drawing]

3.2 Please have a look at your picture again and indicate which statement describes it best:

The picture i have drawn is;

... characterized by very negative associations

... characterized by negative associations

... neutral

... characterized by positive associations

... characterized by very positive associations

3.3 Which words spontaneously come to your mind when you think of geothermal energy?
a.
b.
c.
d. 
3.4 Please indicate for each word which you mentioned in question 3.3, whether you associate it with negative, neutral or positive associations.

(Answers for each word: very negative associations, negative associations, neutral, positive associations, very positive associations)

a.

b.

c.

d.

3.5 Which color do you spontaneously associate with geothermal energy:

\section{Demographic details}

To finalize, please answer the following two questions on your demographics:

- Gender (male/female)

- Age

Thank you for your participation.

In case you have any further comments on the survey, you are welcome to note them here: 